\title{
Characterization of a set of abdominal neuroendocrine cells that regulate stress physiology using colocalized diuretic peptides in Drosophila
}

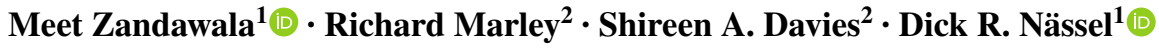

Received: 11 June 2017 / Revised: 1 October 2017 / Accepted: 6 October 2017 / Published online: 17 October 2017

(C) The Author(s) 2017. This article is an open access publication

\begin{abstract}
Multiple neuropeptides are known to regulate water and ion balance in Drosophila melanogaster. Several of these peptides also have other functions in physiology and behavior. Examples are corticotropin-releasing factor-like diuretic hormone (diuretic hormone 44; DH44) and leucokinin (LK), both of which induce fluid secretion by Malpighian tubules (MTs), but also regulate stress responses, feeding, circadian activity and other behaviors. Here, we investigated the functional relations between the LK and DH44 signaling systems. DH44 and LK peptides are only colocalized in a set of abdominal neurosecretory cells (ABLKs). Targeted knockdown of each of these peptides in ABLKs leads to increased resistance to desiccation, starvation and ionic stress. Food ingestion is diminished by knockdown of DH44, but not LK, and water retention is increased by LK knockdown only. Thus, the two colocalized peptides display similar systemic actions, but differ with respect to regulation of feeding and body water retention. We also demonstrated that DH44 and LK have additive effects on fluid secretion by MTs. It is likely that the colocalized peptides are coreleased from ABLKs into the circulation
\end{abstract}

Electronic supplementary material The online version of this article (doi:10.1007/s00018-017-2682-y) contains supplementary material, which is available to authorized users.

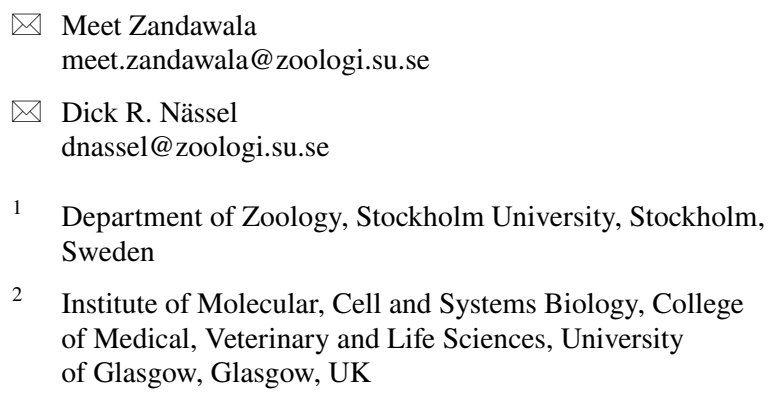

Meet Zandawala

meet.zandawala@zoologi.su.se

Dick R. Nässel

dnassel@zoologi.su.se

1 Department of Zoology, Stockholm University, Stockholm, Sweden

2 Institute of Molecular, Cell and Systems Biology, College of Medical, Veterinary and Life Sciences, University of Glasgow, Glasgow, UK

and act on the tubules where they target different cell types and signaling systems to regulate diuresis and stress tolerance. Additional targets seem to be specific for each of the two peptides and subserve regulation of feeding and water retention. Our data suggest that the ABLKs and hormonal actions are sufficient for many of the known DH44 and LK functions, and that the remaining neurons in the CNS play other functional roles.

Keywords Diuretic hormone $44 \cdot$ Corticotropin-releasing factor-like diuretic hormone $\cdot$ Leucokinin $\cdot$ Peptide hormones $\cdot$ Stress resistance

\section{Introduction}

Orchestration of physiological and behavioral processes is commonly dependent on neuropeptide and peptide hormone signaling (see [1-4]). For example, feeding and postprandial effects on the organism, including satiety, nutrient and energy reallocation, diuresis, and activity/sleep are regulated by multiple peptides (see [1, 3, 5-9]). Thus, in Drosophila melanogaster, several neuropeptides such as allatostatin A, neuropeptide $\mathrm{F}$, short neuropeptide $\mathrm{F}$ ( $\mathrm{sNPF}$ ), sulfakinin, and hugin-pyrokinin are known to regulate feeding, and five peptides, diuretic hormones 31 and 44, leucokinin as well as CAPA-1 and 2, derived from the gene capability, regulate ion and water homeostasis (see [1, 3, 7, 10-13]). After a meal, other hormones, such as insulin-like peptides (ILPs) and adipokinetic hormone (AKH), ensure energy mobilization and storage, or signal satiety/hunger and affect organismal activity, vigor, and stress tolerance [7, 14-16].

The neuroendocrine cells producing the peptides mentioned above display varying degrees of diversity, from a single small set of identical cells producing AKH or ILPs to 
very large populations of diverse neurons expressing sNPF [17-19]. Thus, the question is whether peptidergic neurons of a large diverse population are functionally coupled and play a concerted physiological role, or if they are parts of distributed networks where the specific neuropeptide therefore serve diverse functions. To address this question, we have selected a set of neuroendocrine cells producing the neuropeptide leucokinin (LK) that consists of four morphological types of cells [20,21], and is proposed to serve multiple functions in flies [6, 22-26]. This set of neurons was dissected by genetic tools to enable us to isolate the functional role of a major subset, which consists of prominent neurosecretory cells in the abdominal ganglia. We show that this subset of the LK neurons, designated ABLKs, additionally produce corticotrophin-releasing factor-like diuretic hormone, also known as diuretic hormone 44 (DH44). These ABLKs are especially intriguing, since they seem to be under tight neuronal and hormonal control. Receptors for several neurotransmitters and peptides have been identified on these cells in larvae [24, 27-32] and adults [24]. Of these receptors, only the action of the 5-HT1B receptor on ABLK function was probed in adults [24]. We ask what function these specific neuroendocrine cells and their colocalized peptide hormones have in physiology and behavior.

Both DH44 and LK are primarily known for their roles as diuretic hormones in various insects, including Drosophila, by regulating secretion by Malpighian (renal) tubules (MTs) [3, 12, 33, 34]. However, several additional functions have been assigned to these peptides from genetic experiments. LK neurons regulate food intake, play a role in desiccation stress resistance, modulate chemosensory responses, decrease postprandial sleep, and are required for starvation-induced sleep suppression [6, 22-26]. DH44, which is produced by a diverse set of neurons and neurosecretory cells [33, 35], plays roles in osmotic and metabolic stresses. Knockdown of DH44 in the CNS or its receptor (DH44-R2) in the MTs results in a significant increase in desiccation tolerance [23]. Genetic ablation of DH44 neurons also results in increased starvation tolerance; however, knockdown of the DH44 receptor, DH44-R2, in the MTs impairs starvation tolerance [23]. Furthermore, DH44 producing median neurosecretory cells in the brain regulate rhythmic locomotor activity with influence from clock cells [36], sense and regulate intake of nutritive carbohydrates [37], and regulate sperm retention in the uterus of females [35].

The postulated functions of LK and DH44 are, with a few exceptions, not assigned to specific neurons. Using the GAL4-UAS system [38], we targeted interference with LK and DH44 expression to the ABLKs and analyzed the in vivo effects on tolerance to various stressors, as well as feeding and water retention. We also employed an assay to monitor the combined activity of DH44 and LK on secretion in MTs. These peptides act on different cell types of the Drosophila MTs and activate different signaling pathways [33, 34], yet we show that they display an additive stimulatory effect on secretion. Thus, we can show that the ABLKs, and therefore hormonal actions of the two peptides, are sufficient for regulating water and ion homeostasis and associated stress functions, but can also affect food intake, perhaps by an indirect action caused by diuretic activity. This suggests that the LK and DH44 neurons in the brain are important for the additional functional roles listed above, and it remains to be determined whether these functions are in any way linked to those of the ABLKs.

\section{Experimental procedures}

\section{Fly lines and husbandry}

All fly strains used in this study (Table 1) were reared and maintained at $25{ }^{\circ} \mathrm{C}$ on a standard yeast, corn meal,

Table 1 Fly strains used in this study

\begin{tabular}{|c|c|c|c|}
\hline Fly strain & $\begin{array}{l}\text { Inserted on chromo- } \\
\text { some }\end{array}$ & Source/reference & Stock number \\
\hline$w^{1118}$ & - & BDSC & - \\
\hline$w^{1118} ; L k-G A L 4$ & II & [21], Pilar Herrera, Madrid, Spain & - \\
\hline$w^{1118} ; L k-G A L 4$ & II & [39] & BDSC 51993 \\
\hline$w^{1118} ; L k-G A L 4$ & III & Young Joon Kim, Gwangju, Korea & - \\
\hline$w^{1118} ; D H 44-G A L 4$ & III & [40], Fly Light & BDSC 39347 \\
\hline$w^{1118} ; D H 44-G A L 4$ & III & {$[39]$} & BDSC 51987 \\
\hline$y^{I} w^{*} ; A c t i n 5 c-G A L 4 / C y O$ & II & - & BDSC 4414 \\
\hline$w^{1118} ; U A S-L k-R N A i$ & III & [41] & VDRC 14091/GD \\
\hline$y w ; U A S-D H 44 R N A i$ & II & - & VDRC 108473/KK \\
\hline yw; Sco/Cyo; UAS-mcd8-GFP & III & BDSC & - \\
\hline JFRC29-10xUAS-IVS-myr::GFP-p10 & - & [42], Washington, USA & - \\
\hline
\end{tabular}


and agar medium (see http://flystocks.bio.indiana.edu/ Fly_Work/media-recipes/bloomfood.htm) supplemented with $1.5 \mathrm{~g} / \mathrm{l}$ nipagin and $3 \mathrm{ml} / \mathrm{l}$ propionic acid. Experimental flies were reared under uncrowded conditions and normal photoperiod (12 h light: $12 \mathrm{~h}$ dark).

\section{Immunohistochemistry and imaging}

Immunohistochemistry for Drosophila larval and adult CNS was performed as described earlier [43]. Briefly, CNS from third instar larvae or adult male flies was dissected in phosphate-buffered saline (PBS). Larval samples were fixed for $2 \mathrm{~h}$ in 5\% ice-cold paraformaldehyde and adult samples were fixed on ice for 3.5-4 h. The samples were then washed with PBS and incubated for $48 \mathrm{~h}$ at $4{ }^{\circ} \mathrm{C}$ in primary antibodies diluted with PBS with $0.5 \%$ Triton X (PBST) (Table 2). Following this incubation, the samples were washed with PBST and incubated for $48 \mathrm{~h}$ at $4{ }^{\circ} \mathrm{C}$ in secondary antibodies diluted with PBST (Table 2). Next, all samples were thoroughly washed with PBST, and following a final wash in PBS, the samples were mounted in $80 \%$ glycerol. For anti-DH44 staining, tissues were blocked with 5\% normal goat serum (NGS) in PBST post-fixation and 5\% NGS was also included in the primary antibody solution.

All samples were imaged with a Zeiss LSM 780 confocal microscope (Jena, Germany) using $10 \times$, $20 \times$, or $40 \times$ oil immersion objectives. Confocal images were processed with Zeiss LSM software and Fiji [45] for projection of z-stacks, contrast and brightness, and calculation of immunofluorescence levels. Cell fluorescence was measured as described previously [43]. Briefly, the cells of interest were selected and their area, integrated density, and mean gray values measured. The background values for these parameters were also recorded by selecting a region that has no fluorescence near the cells of interest. The corrected total cell fluorescence (CTCF) was then calculated using the equation: $\mathrm{CTCF}=$ integrated density - (area of selected cell $\times$ mean fluorescence of background readings).

\section{Stress resistance assays}

We used 5- to 6-day-old male flies to assay for survival under various stresses and recovery from chill coma (see [43] for details of stress assays). For each technical replicate, 15 flies were kept in a vial and their survival recorded every $3 \mathrm{~h}$ (for desiccation) or $6 \mathrm{~h}$ (for starvation and ionic stress) until all the flies were dead. For desiccation, flies were kept in empty vials. For starvation, flies were kept in vials containing $5 \mathrm{ml}$ of $0.5 \%$ aqueous agarose (A2929, Sigma-Aldrich). For ionic stress, flies were kept in vials containing $5 \mathrm{ml}$ enriched medium ( $100 \mathrm{~g} / \mathrm{l}$ sucrose, $50 \mathrm{~g} / \mathrm{l}$ yeast, $12 \mathrm{~g} / \mathrm{l}$ agar, $3 \mathrm{ml} / \mathrm{l}$ propionic acid, and $3 \mathrm{~g} / \mathrm{l}$ nipagin), supplemented with $4 \%$ $\mathrm{NaCl}$. All vials were kept at $25^{\circ} \mathrm{C}$ under normal photoperiod conditions for the entire duration of the experiment. For chill coma recovery experiments, flies were transferred to empty vials, which were then placed on ice to induce a chill coma. The vials were incubated on ice $\left(0{ }^{\circ} \mathrm{C}\right)$ for $4 \mathrm{~h}$ and afterward transferred to $25^{\circ} \mathrm{C}$ to induce recovery. The number of flies recovered was assessed every $2 \mathrm{~min}$. At least three biological replicates and three technical replicates for each biological replicate were performed for each experiment.

\section{Capillary feeding assay}

Capillary feeding (CAFE) assay to measure food intake for individual flies was performed according to the method described earlier [24]. Food consumption was measured daily and the cumulative food intake over 4 days was calculated. The experiment consisted of three biological replicates and eight to ten flies per replicate for each genotype.

\section{Water content measurement}

For measurement of water content, 10-15 flies were frozen on dry ice and their weight (wet weight) recorded using a Mettler Toldeo MT5 microbalance (Columbus, USA). The flies were then dried for 1 day at $60^{\circ} \mathrm{C}$ and their weight (dry weight) recorded again. The water content of the flies was determined by subtracting dry weight from wet weight (see [46]).
Table 2 Antibodies used for immunohistochemistry

\begin{tabular}{llll}
\hline Antibody & Immunogen & Source/reference & Dilution \\
\hline Primary antibody & & & \\
Rabbit anti-LK & Leucophaea maderae kinin I & {$[44]$} & $1: 2000$ \\
Rabbit anti-DH44 & Drosophila melanogaster DH44 & [33] Jan Veenstra, & $1: 1000$ \\
& & Bordeaux, France & \\
Mouse anti-GFP & Jelly fish GFP & Invitrogen & $1: 1000$ \\
Secondary antibody & & & \\
Goat anti-mouse Alexa 488 & - & Invitrogen & $1: 1000$ \\
Goat anti-rabbit Alexa 546 & - & Invitrogen & $1: 1000$ \\
\hline
\end{tabular}



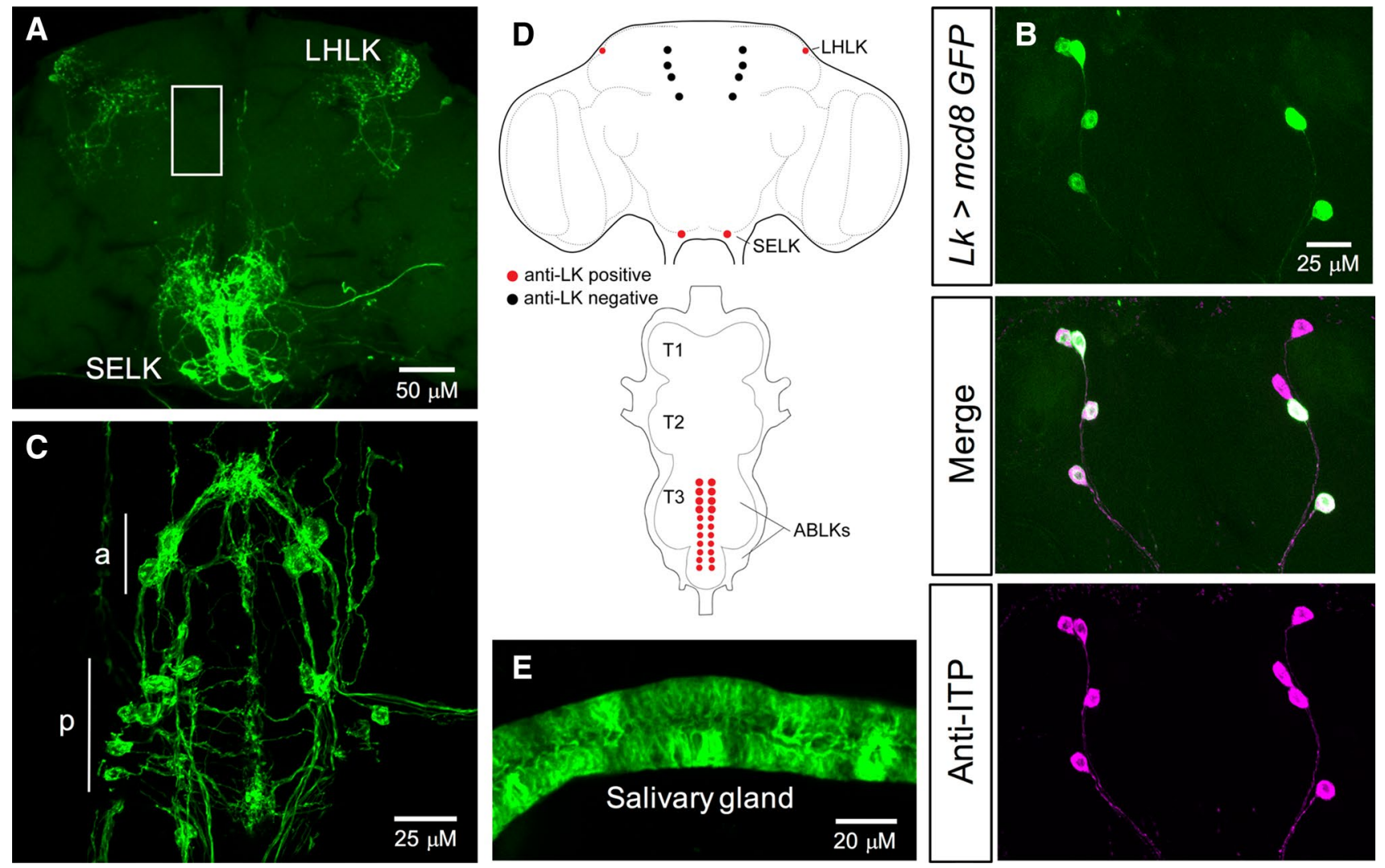

Fig. 1 The $L k$-GAL4 drives GFP expression in four distinct neuronal populations in the adult Drosophila CNS. a One pair of neurons in the lateral horn (lateral horn LK neurons; LHLKs) and another pair of neurons in the subesophageal ganglion (subesophageal ganglion LK neurons; SELKs) express LK in adult brain of Drosophila. $L k$ GAL4 also drives weak and variable expression in four pairs of neurons in the brain (approximate location of these cells is indicated by the white box; see Figure S2 for an alternate preparation where these cells are weakly stained). b These four pairs of neurons do not display any LK-immunoreactivity, but are positive for ITP-immunoreactivity

\section{Malpighian tubule secretion assay}

Drosophila MT fluid secretion assays were performed as described previously [47]. Briefly, MTs from 6-day-old Drosophila were dissected in Schneider's medium and transferred to $9 \mu \mathrm{l}$ of $50 \%$ Schneider's medium and $50 \%$ Drosophila saline [33]. Tubules were left to secrete for $30 \mathrm{~min}$ and non-secreting tubules were replaced to form a data set of 10-15 secreting tubules. Basal secretion was measured for $30 \mathrm{~min}$ at $10 \mathrm{~min}$ intervals. Following this initial incubation, $1 \mu$ of Drosophila DH44 (final concentration $10^{-7}$ or $10^{-9} \mathrm{M}$ ), LK (final concentration $10^{-9}$ or $10^{-10} \mathrm{M}$ ), or both (Genosphere Biotechnologies, Paris, France) was added to the incubation medium. Stimulated secretion was measured for $30 \mathrm{~min}$ at $10 \mathrm{~min}$ intervals. Data are presented as the secretion rate at every time point, the percentage change in
[21]. $\mathbf{c}$ In the ventral nerve cord (VNC), LK is expressed in 11 pairs of neurons (abdominal LK neurons; ABLKs). Seven pairs of smaller neurons in the posterior region $(\mathrm{p})$ persist from the larval stages and the other four pairs (the number of pairs can vary between individuals) of larger neurons in the anterior region (a) are adult specific [48]. d A schematic depiction of LK-expressing neurons in the adult brain and VNC of Drosophila. T1-T3, thoracic neuromeres. e $L k-G A L 4$ also drives ectopic expression in the salivary glands of adult Drosophila. JFRC29-10xUAS-IVS-myr::GFP-p10 was utilized in a, $\mathbf{c}$ and $\mathbf{e}$, whereas $U A S-m c d 8-G F P$ was utilized in $\mathbf{b}$

secretion rate following peptide application, and total fluid secreted over $60 \mathrm{~min}$.

\section{Statistical analyses}

The experimental data are presented as means \pm SEM. Unless stated otherwise, one-way analysis of variance (ANOVA) followed by Tukey's multiple comparisons test was used for comparisons between three genotypes and an unpaired $t$ test was used for comparisons between two genotypes. For fluid secretion assays, a Mann-Whitney $U$ test was used as some data were non-normally distributed. Stress curves were compared using Mantel-Cox log-rank test. All statistical analyses were performed using GraphPad Prism with a 95\% confidence limit $(p<0.05)$. 


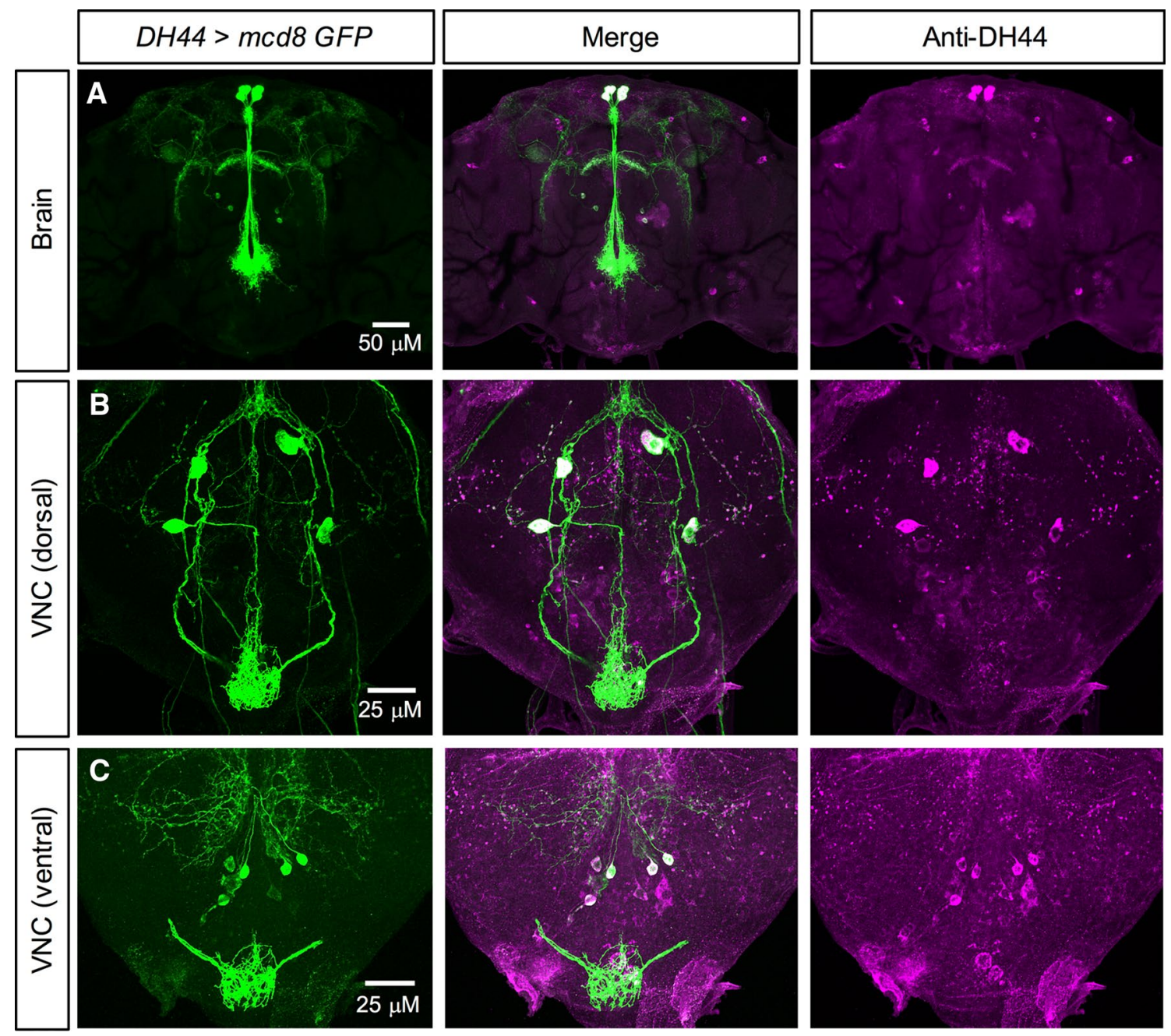

Fig. 2 DH44 expression in the adult Drosophila CNS. a DH44 is expressed in three pairs of median neurosecretory cells (MNCs) in pars intercerebralis of adult Drosophila. Antiserum to Drosophila DH44 labels the same neurons identified by DH44-GAL4-driven GFP. b In the dorsal region of the ventral nerve cord (VNC), DH44 is expressed in two pairs of neurons. $\mathbf{c}$ In the ventral region of the VNC, DH44 is expressed in at least four pairs of neurons. In both $\mathbf{b}$ and $\mathbf{c}$, there are some neurons that display DH44-immunoreactivity, but do not express GFP

\section{Results}

\section{LK expression in Drosophila CNS}

Several studies have previously examined the distribution of LK in Drosophila CNS and peripheral tissues [20, 21, 23, 24, 48]. Here, we verified the expression of $L k$-GAL4-driven GFP in both larval (Figure S1A-E) and adult Drosophila (Fig. 1), using a GAL4 line from De Haro et al. [21]. In the larval CNS, $L k$-GAL4 drives the expression in five pairs of neurons in the brain (Figure S1A, E), three pairs of neurons in the SOG (Figure S1C, E), and seven pairs of neurons in the VNC (Figure S1D, E). However, four out of the five pairs in the brain do not display any LK-immunoreactivity, but in fact react with an antiserum to ion transport peptide (ITP) (Figure S1B). These lateral neurosecretory cells are found both in larval and adult brains and are known as ipc-1 neurons [49]. Similar to the larval CNS, $L k$-GAL4 drives GFP expression in four distinct neuronal populations in the adult CNS (Fig. 1). Hence, GFP expression was detected in 1 pair of neurons in the lateral horn and 1 pair in the SOG (Fig. 1a, d), 4 other pairs in the brain, which display ITPimmunoreactivity (Fig. 1b, d, S2), and 11 pairs in the VNC (Fig. 1c, d). In adult flies, Lk-GAL4-driven GFP expression in the ITP-producing cells is weak and variable (Figure S2). Interestingly, seven pairs of neurons in the VNC 

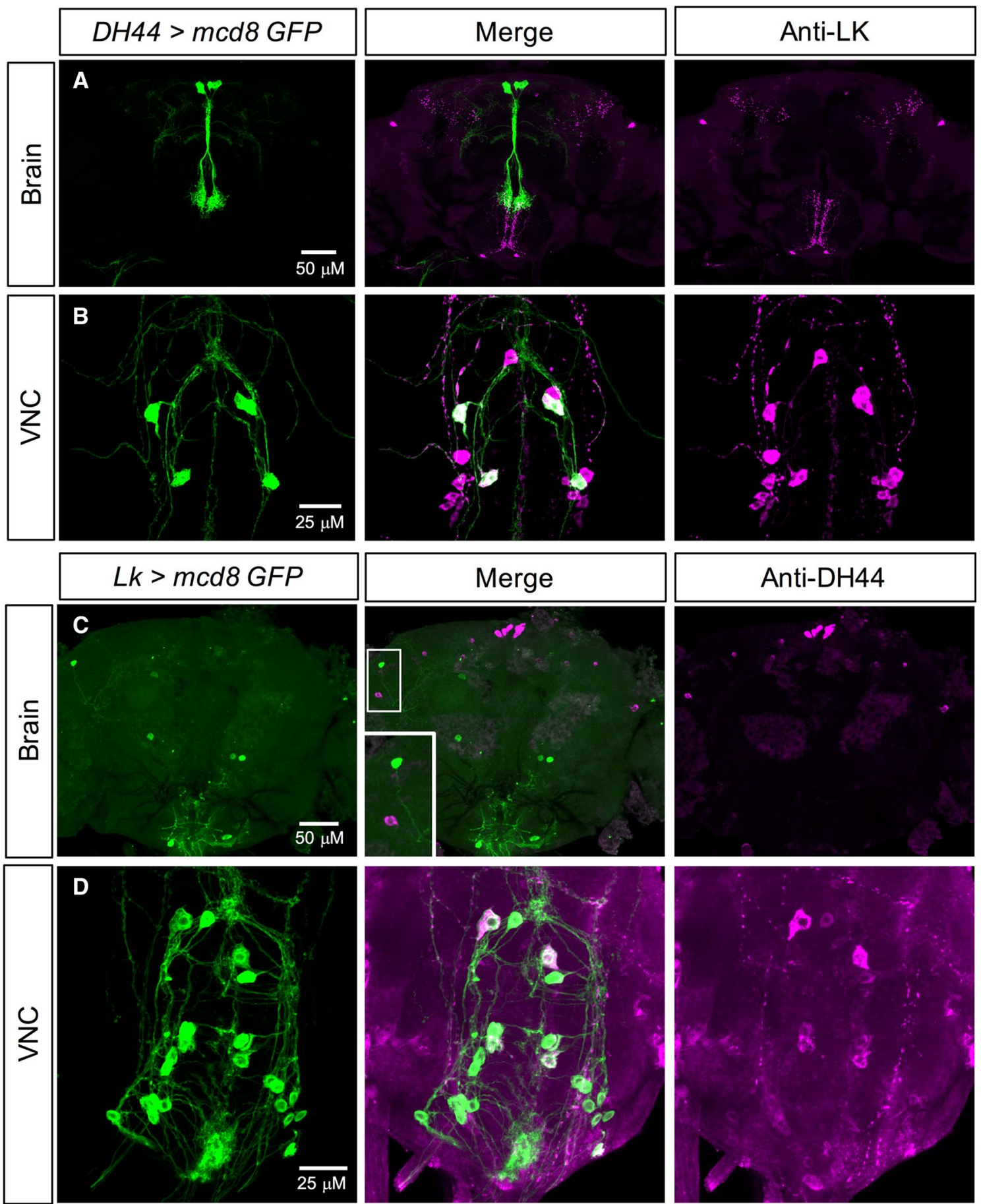

Fig. 3 LK and DH44 are co-expressed in the ventral nerve cord, but not in the brain of adult Drosophila. a DH44-GAL4-driven GFP is not colocalized with LK-immunoreactivity in the adult brain. b $\mathrm{DH} 44$ GAL4-driven GFP is colocalized with LK-immunoreactivity in a sub-

start expressing LK in the embryonic stage, whereas the additional four pairs (this number varies between individuals) begin to express LK during pupal development [48]. set of the abdominal LK neurons (ABLKs) in the ventral nerve cord (VNC). c $L k$-GAL4-driven GFP is not colocalized with DH44-immunoreactivity in the adult brain. d $L k$-GAL4-driven GFP is colocalized with DH44-immunoreactivity in a subset of ABLKs in the adult VNC

Moreover, $L k$-GAL4 also drives ectopic expression in salivary glands (Fig. 1e). Although we tested two additional $L k$-GALA driver lines (Table 1), we utilized this $L k-G A L A$ for 
A
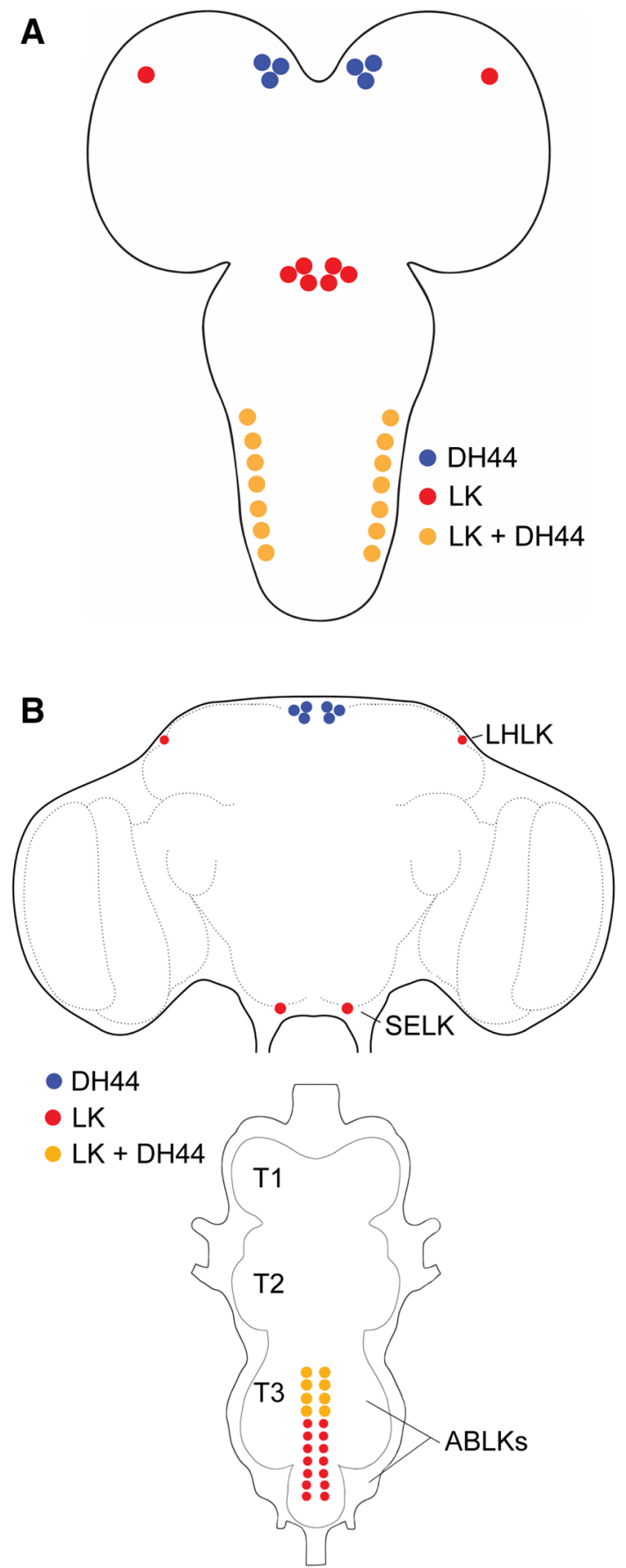

Fig. 4 Schematics of LK- and DH44-expressing neurons in the larval and adult CNS of Drosophila. a A schematic of the larval CNS showing the location of neurons expressing LK, DH44, or both LK and DH44. b A schematic of the adult CNS showing the location of neurons expressing LK, DH44, or both LK and DH44. LHLK, lateral horn LK neuron; SELK, subesophageal ganglion LK neuron; ABLK, abdominal LK neuron, T1-T3, thoracic neuromeres

subsequent knockdown experiments because its expression is stronger than, or more specific than, the other $L k-G A L 4$ lines (Table 1; data not shown).
DH44 is expressed in the Drosophila brain and ventral nerve cord

DH44 expression in Drosophila has also been examined and mapped previously [33, 35]. However, different GAL4 lines result in differing expression patterns. Thus, we validated the expression of two previously generated $\mathrm{DH} 44-\mathrm{GAL} 4$ lines $[39,40]$. One of these GAL4 lines has a minimal expression pattern and drives GFP expression in only the six MNCs in the brain (data not shown) [39]. The other DH44-GAL4 line, which was obtained from the FlyLight collection [40], resulted in a good overlap between $D H 44>G F P$ and DH44immunoreactivity. This $D H 44-G A L 4$ drives GFP expression broadly in larval (Figure S1F, G) and adult CNS (Fig. 2). In larvae, predominant expression was detected in the six MNCs in the brain (Figure S1F) and seven pairs of neurosecretory cells in the VNC (Figure S1G); however, some of these cells in the $\mathrm{VNC}$ were not visible in both hemiganglia. In adults, expression was again detected in the six MNCs (Fig. 2a) and at least four cells dorsally (Fig. 2b) and at least six cells ventrally in the posterior VNC (Fig. 2c). Since there was a good overlap in GFP expression and DH44-immunoreactivity, we utilized this DH44-GAL4 for subsequent knockdown manipulations.

\section{LK and DH44 are co-expressed in larval and adult ABLK neurons}

The functional overlap between LK and DH44 signaling systems mentioned earlier, coupled with the expression of both LK and DH44 in the VNC neurons, prompted us to examine if these two neuropeptides are co-expressed in subsets of neurons. Our expression data show that there is no overlap in LK and DH44 expression in the brain of larvae (Figs. S3A, C, 4a) or adults (Figs. 3a, c, 4b), but these neuropeptides are co-expressed in the larval (Figs. S3B, D, Fig. 4a) and several adult ABLKs (Figs. 3b, d, 4b). Interestingly, all the larval ABLKs co-express DH44, but in adults only four to eight ABLKs express DH44 (Fig. 4). Furthermore, the majority of these DH44 expressing ABLKs in the adults appear to be the ones that are generated during postembryonic neurogenesis. However, we cannot rule out the possibility that DH44 is present with a very low expression in other ABLKs.

\section{Knockdown of Lk with Lk-GAL4 impacts stress response and water content}

Having shown that LK and DH44 are co-expressed in ABLKs, it now becomes apparent that the previous studies employing genetic ablation and activation or inactivation of LK neurons could be confounded by effects of diminishing signaling with two colocalized peptides [23-25]. Thus, it is not only timely to dissect the behavioral phenotypes from 

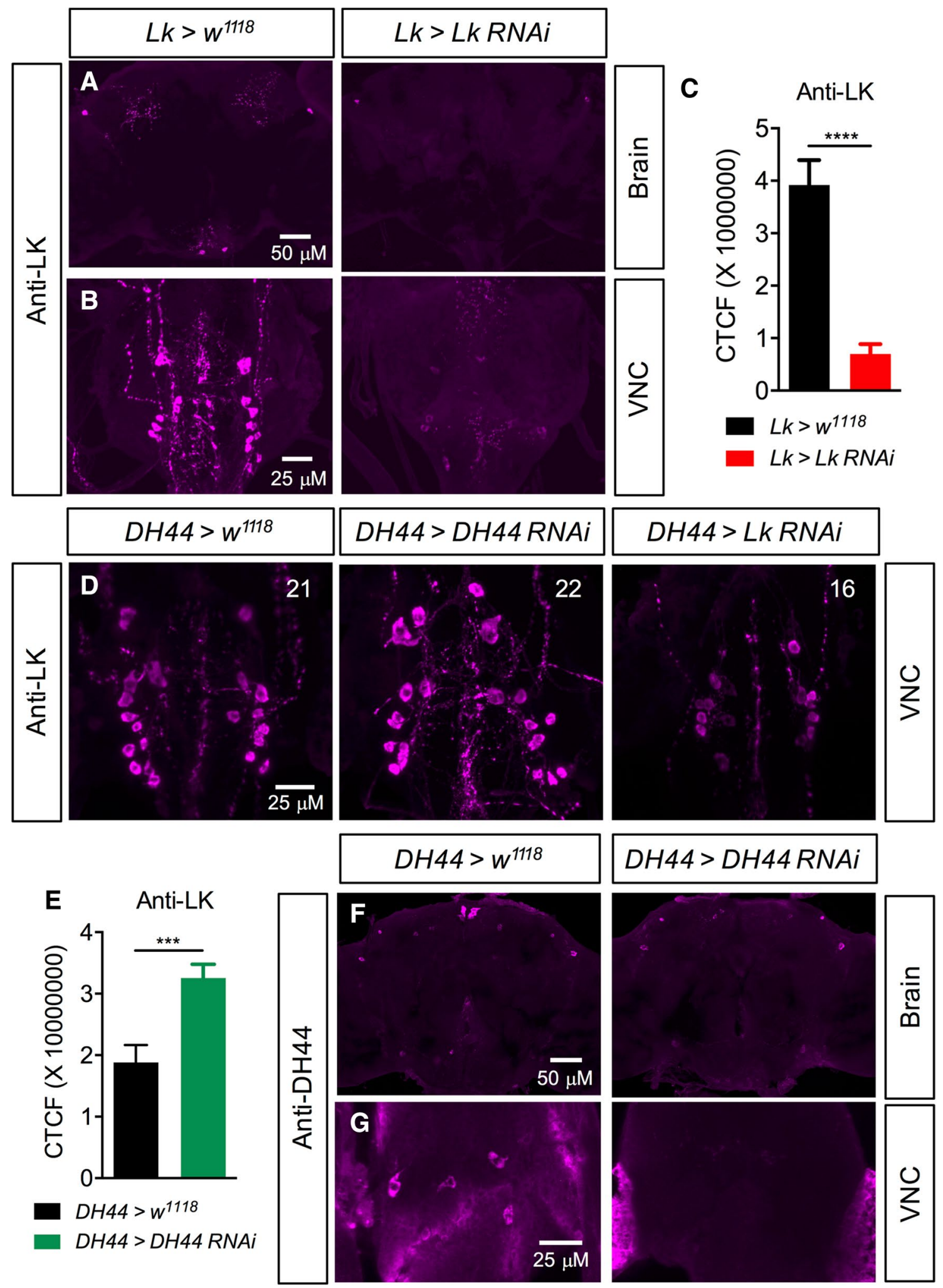

these previous studies using RNAi-based knockdown, but we can also study the specific functions of ABLKs using intersectional crosses. Consequently, we utilized $L k-G A L 4$ and DH44-GAL4 to knock down both $L k$ and $D H 44$ and assayed for effects on stress tolerance, feeding, and water content. As controls in all experiments, we used the parental GAL4 and UAS lines (in $w^{1118}$ background) crossed to $w^{1118}$ flies. 
4Fig. $5 L k$ - and DH44-RNAi knockdown efficiency was tested using immunolabelling. a, b Knockdown of $L k$ with $L k$-GAL4driven $L k$ $R N A i$ causes a significant decrease in LK-immunoreactivity in the adult brain and ventral nerve cord (VNC). $* * * * p<0.0001$, as assessed by unpaired $t$ test. c Fluorescence intensity measurement of lateral horn LK neurons shows a significant decrease in LK-immunoreactivity in $L k$ knockdown flies compared to control flies. CTCF corrected total cell fluorescence. d $D H 44-G A L 4$-driven $L k-R N A i$ causes a significant decrease in LK-immunoreactivity in the adult VNC as determined by the number of immunoreactive neurons (the average number of neurons is indicated in each panel; see Figure S6) that could be detected. However, DH44-GAL4-driven DH44-RNA causes a significant increase in LK-immunoreactivity in adult ABLKs $(* * * p<0.001$, as assessed by unpaired $t$ test). (e) and a complete abolishment of DH44-immunoreactivity in the adult brain (f) and VNC (g)

$L k$-GAL4-driven $L k-R N A i$ results in a significant decrease in LK-immunoreactivity in both the brain (Fig. 5a, c) and VNC (Fig. 5b). These flies with $L k$ knockdown display increased survival under desiccation (Fig. 6a), starvation (Fig. 6b), and ionic stress (Fig. 6c), but there is no difference in chill coma recovery between experimental and control flies (Fig. 6d). Moreover, food intake in CAFE assay is not affected by $L k$ knockdown (Fig. 6e) (see also [22]), but these flies retain more water (Fig. 6f) as demonstrated earlier [24, 50]. Previous work had shown that inactivation of LK neurons resulted in increased survival under desiccation, but had no impact on starvation resistance [24]. Furthermore, in that study, both the activation and inactivation of LK neurons caused the flies to feed less in CAFE assay. This was in contrast to another study employing LK and LKR mutants, which did not find altered overall food intake, but rather an increase in meal size [22]. Hence, our data on desiccation are in agreement with previous findings and clarify the discrepancies in previous results on food intake as possibly caused by the presence of another neuroactive compound in the LK neurons that affects feeding. The data are summarized in Table 3.

\section{Knockdown of DH44 with Lk-GAL4 impacts stress response and feeding}

We verified the efficiency of $\mathrm{DH} 44$ knockdown using a ubiquitous driver (Actin 5c-GAL4) and a specific driver (DH44-GAL4). Knockdown of DH44 with both these drivers results in a significant decrease in DH44-immunoreactivity (Fig. 5f, g, S4). We then utilized $L k-G A L 4$ to knock down DH44 specifically in ABLKs, which resulted in increased survival under desiccation (Fig. 7a), starvation (Fig. 7b), and ionic stress (Fig. 7c), and these flies display delayed recovery from chill coma compared to control flies (Fig. 7d). Interestingly, $\mathrm{DH} 44$ knockdown flies feed less in the CAFE assay (Fig. 7e), but display no difference in water content compared to controls (Fig. 7f). Hence, it appears that the effect of decreased feeding following LK neuron inactivation can be attributed to the presence of DH44 in ABLKs. Furthermore, LK but not DH44 has an effect on water content. Perhaps, this could be due to the fact that LK is a more potent diuretic than DH44 in Drosophila and hence DH44 cannot fully compensate for the lack of LK [33, 34]. Alternatively, LK could also impact water retention via actions on the hindgut $[51,52]$. Data are summarized in Table 3.

\section{Knockdown of Lk with DH44-GAL4 impacts stress response and water content}

Next, we wanted to determine the effects of knocking down $L k$ in adult-specific ABLKs. We first confirmed that $D H 44-$ GAL4-driven $L k-R N A i$ results in an efficient knockdown in adult-specific ABLKs by counting the number of cells positive for LK-immunoreactivity (Figs. 5d, S5). The average number of cells stained for LK-immunoreactivity in the control flies was 21 , whereas the knockdown flies only had an average of 16 cells. Moreover, the larger adult-specific ABLKs are not labeled in the knockdown flies, validating that the knockdown is efficient. Knockdown of $L k$ with DH44-GAL4 results in increased survival during desiccation (Fig. 8a), starvation (Fig. 8b), ionic stress (Fig. 8c), as well as a significant delay in recovery from chill coma (Fig. 8d). Similar to the global $L k$ knockdown with $L k-G A L 4, L k$ knockdown in ABLKs has no effect on feeding (Fig. 8e), but results in a significant increase in the water content of the flies (Fig. 8f). This suggests that the effects of LK on stress response and water content could be attributed to ABLKs, and perhaps the LHLKs and SELKs of the brain play little to no part in these processes. Data are summarized in Table 3.

\section{Knockdown of DH44 with DH44-GAL4 impacts stress response and feeding}

Knockdown of DH44 with $\mathrm{DH} 44-\mathrm{GAL} 4$ results in an efficient knockdown in the brain (Fig. 5f) and VNC (Fig. 5g). Staining is abolished in MNCs, but not in the other cells in the brain suggesting that staining in those cells is not specific for DH44 (Fig. 5f). To determine if there is any interaction between LK and DH44 signaling, we measured LK peptide levels in ABLKs of $\mathrm{DH} 44$ knockdown flies. Interestingly, flies with $\mathrm{DH} 44$ knockdown have higher LK levels suggesting that the flies may compensate for the lack of DH44 with increased LK expression (Fig. 5d, e). Moreover, flies with global $\mathrm{DH} 44$ knockdown display no effects on survival during desiccation (Figure S6A), but show increased resistance to starvation (Figure S6B), ionic stress (Figure S6C), and a small but significant delay in their recovery from chill coma (Figure S6D). Furthermore, flies with $\mathrm{DH} 44$ knockdown display no difference in feeding (Figure S6E) and water content 

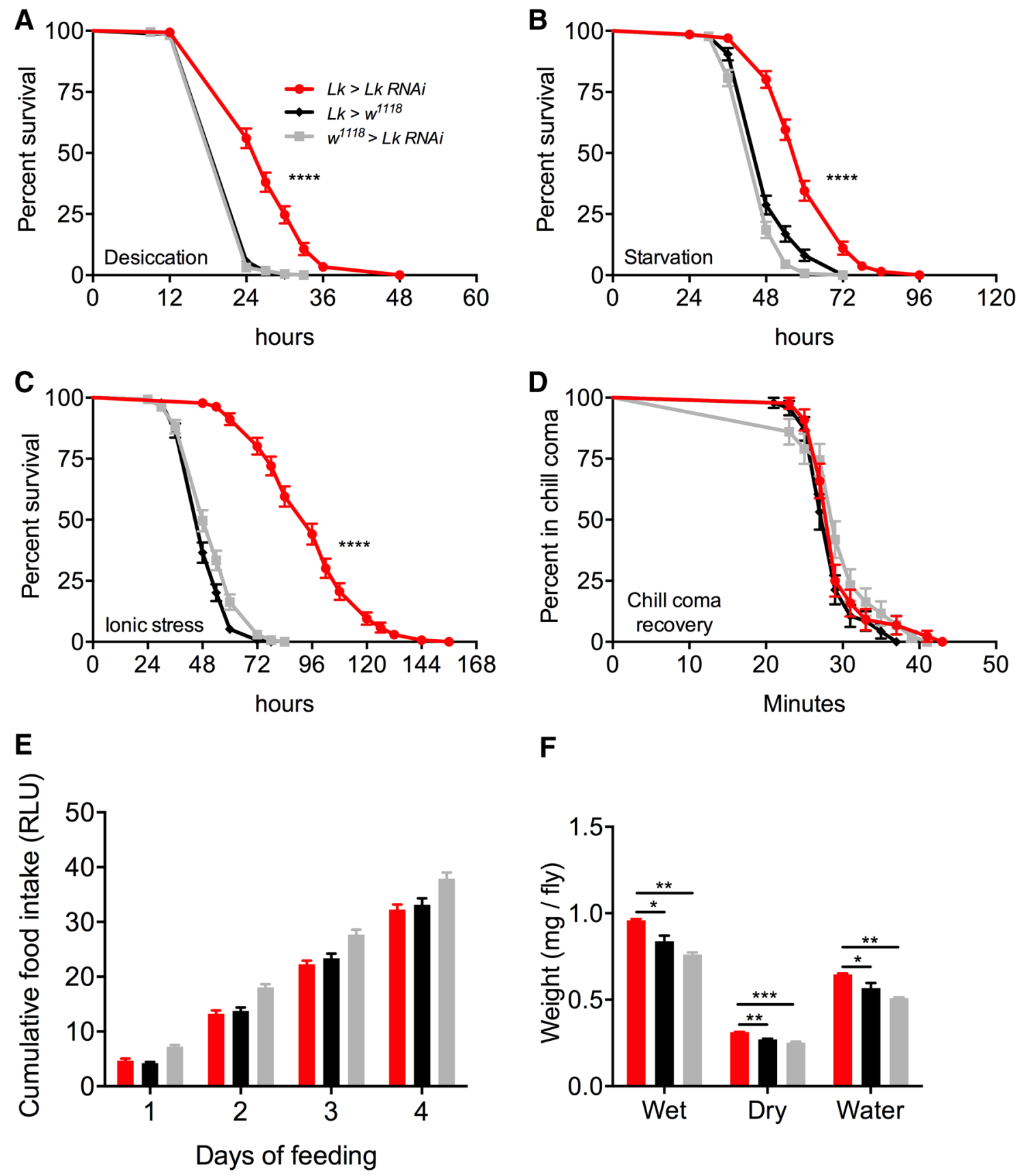

$\mathbf{F}$

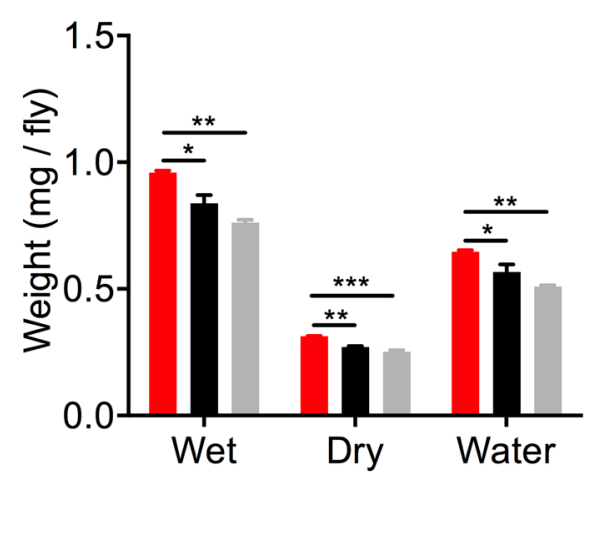

Fig. 6 Knockdown of $L k$ using $L k-G A L 4$ impacts stress resistance and water content of Drosophila. Lk-GAL4-driven $L k$ knockdown results in a significant increase in survival compared to control flies under a desiccation, b starvation, and $\mathbf{c}$ ionic stress (artificial food supplemented with $4 \% \mathrm{NaCl}$ ). Data are presented in survival curves and the error bars represent standard error $(* * * * p<0.0001$, as assessed by log-rank (Mantel-Cox) test. d $L k$ knockdown has no impact on chill coma recovery. e There is no significant differ-

ence (one-way ANOVA) in feeding as measured by capillary feeding (CAFE) assay between $L k$ knockdown and control flies. Results are presented as cumulative food intake over 4 days. f Flies with $L k$ knockdown have a higher wet weight and dry weight and retain more water (wet weight minus dry weight) compared to control flies. $(* p<0.05, * * p<0.01, * * * p<0.001$, as assessed by one-way ANOVA). Legend for $\mathbf{b}-\mathbf{f}$ is the same as the one in $\mathbf{a}$ 
Table 3 Summary of the phenotypes obtained following different manipulations to LK and DH44 signaling. Data are compiled from Figs. 6, 7, 8 , S6

\begin{tabular}{|c|c|c|c|c|}
\hline Assay & $\mathrm{LK}>\mathrm{LK} \mathrm{Ri}$ & DH44>LK Ri & DH44>DH44 Ri & LK>DH44 Ri \\
\hline Effect of manipulation & Global LK knockdown & LK knockdown in ABLKs & Global DH44 knockdown & $\begin{array}{l}\text { DH44 knock- } \\
\text { down in } \\
\text { ABLKs }\end{array}$ \\
\hline Desiccation survival & $\uparrow * * * *$ & $\uparrow * * * *$ & No effect & $\uparrow * * * *$ \\
\hline Starvation survival & $\uparrow * * * *$ & $\uparrow * * * *$ & $\uparrow * * * *$ & $\uparrow * * * *$ \\
\hline Ionic stress survival & $\uparrow * * * *$ & $\uparrow * * * *$ & $\uparrow * * * *$ & $\uparrow * * * *$ \\
\hline Chill coma recovery & No effect & $\uparrow^{*}$ & $\uparrow *$ & $\uparrow *$ \\
\hline Feeding & No effect & No effect & No effect & $\downarrow * * * *$ \\
\hline Water content & $\uparrow * *$ & $\uparrow * * * *$ & No effect & No effect \\
\hline
\end{tabular}

$\uparrow$ Increase, $\downarrow$ decrease, $* p<0.05, * * p<0.01, * * * * p<0.0001$

(Figure S6F) compared to control flies. Data are summarized in Table 3.

\section{LK and DH44 act additively on Malpighian tubules to stimulate fluid secretion}

Since LK and DH44 are co-expressed in ABLKs, they could potentially be coreleased into the hemolymph and result in functional interaction at the target tissue. One such site of interactions is the MTs, since both these peptides stimulate MT secretion, albeit by action on different cell types and via different receptors, second messengers, and ultimate targets $\left(\mathrm{Cl}^{-}\right.$channels for LK and V-ATPase for DH44) [33, 34, 53]. Hence, we were interested in examining the secretion rates by MTs and the volume of secreted fluid in the presence of either peptide alone or in the presence of both (Fig. 9). Our results show that the addition of both LK and DH44 (DH44 at two concentrations) results in a secretion rate that is approximately the sum of the secretion rates obtained following the addition of each of those peptides separately (Fig. 9a-d, Table 4). This additive effect is more prominent when using a higher dose of DH44 $\left(10^{-7} \mathrm{M}\right.$ instead of $10^{-9}$ M) (Fig. 9c, d). The amount of fluid secreted with peptide stimulation is also a reflection of these increased secretion rates (Fig. 9e, f). Hence, $10^{-7} \mathrm{M}$ DH44 and $10^{-10} \mathrm{M}$ LK result in almost identical volumes of fluid secreted (Fig. 9e), whereas a combination of both those peptides doubles the volume of fluid secreted indicating an additive response.

\section{Knockdown of Lk in ABLKs does not influence LK-stimulated Malpighian tubule secretion}

Previous studies have shown that knockdown of peptides could influence the expression of their receptors and vice versa (see [43]). We wanted to determine whether knockdown of $L k$ in ABLKs, the only source of hormonal LK, affects the expression of LKR in MTs, thus influencing LK-stimulated secretion by MTs. Our results indicate that there is no significant difference in LK-stimulated $\left(10^{-9}\right.$ and $10^{-10} \mathrm{M}$ ) secretion rates of MTs isolated from $D H 44>L k$ $R N A i$ and control flies (Figure S7). This is similar to previous work where DH44 $\left(10^{-7} \mathrm{M}\right)$ secretion rates were similar in tubules isolated from $D H 44>D H 44 R N A i$ and control flies [23]. These results are in agreement with the in vivo experiments where flies with $L k$ knockdown display increased survival under desiccation.

\section{Discussion}

Our study reveals that a portion of the LK-expressing neurosecretory cells (ABLKs) in abdominal ganglia co-express DH44, similar to earlier findings in the moth Manduca sexta [54], the locust Locusta migratoria [55], and blood-sucking bug Rhodnius prolixus [56]. Colocalization of these peptides in multiple insect orders, including basal orders, suggests that this colocalization and the subsequent functional interaction between these signaling systems evolved early on during insect evolution. Since ABLKs are the sole neurons producing both peptides in Drosophila, we were able to use GAL4 lines to knock down each of the two peptides in these cells only and thereby isolate the contribution of the ABLKs to the physiology. This enabled us to establish that these neuroendocrine cells are sufficient for many of the functions assigned to DH44 and LK and therefore these functions are hormonally mediated. In contrast, earlier studies were based upon altering peptide levels or activity in entire populations of DH44 and LK neurons [6, 22-26]. Also, we showed here that the $L K-G A L 4$ driver includes a set of ectopic brain cells (ipc-1) that do not express LK, but another peptide ITP. The ipc-1 neurons produce SNPF and tachykinin in addition to ITP and have been found to regulate stress responses [46]. This means that in earlier studies, where the $L K$-GAL4 line was used to inactivate or activate neurons (see e.g., [24, 25]), additional phenotypes are likely to have arisen. Using our approach, where we target only ABLK neurons, we find that 

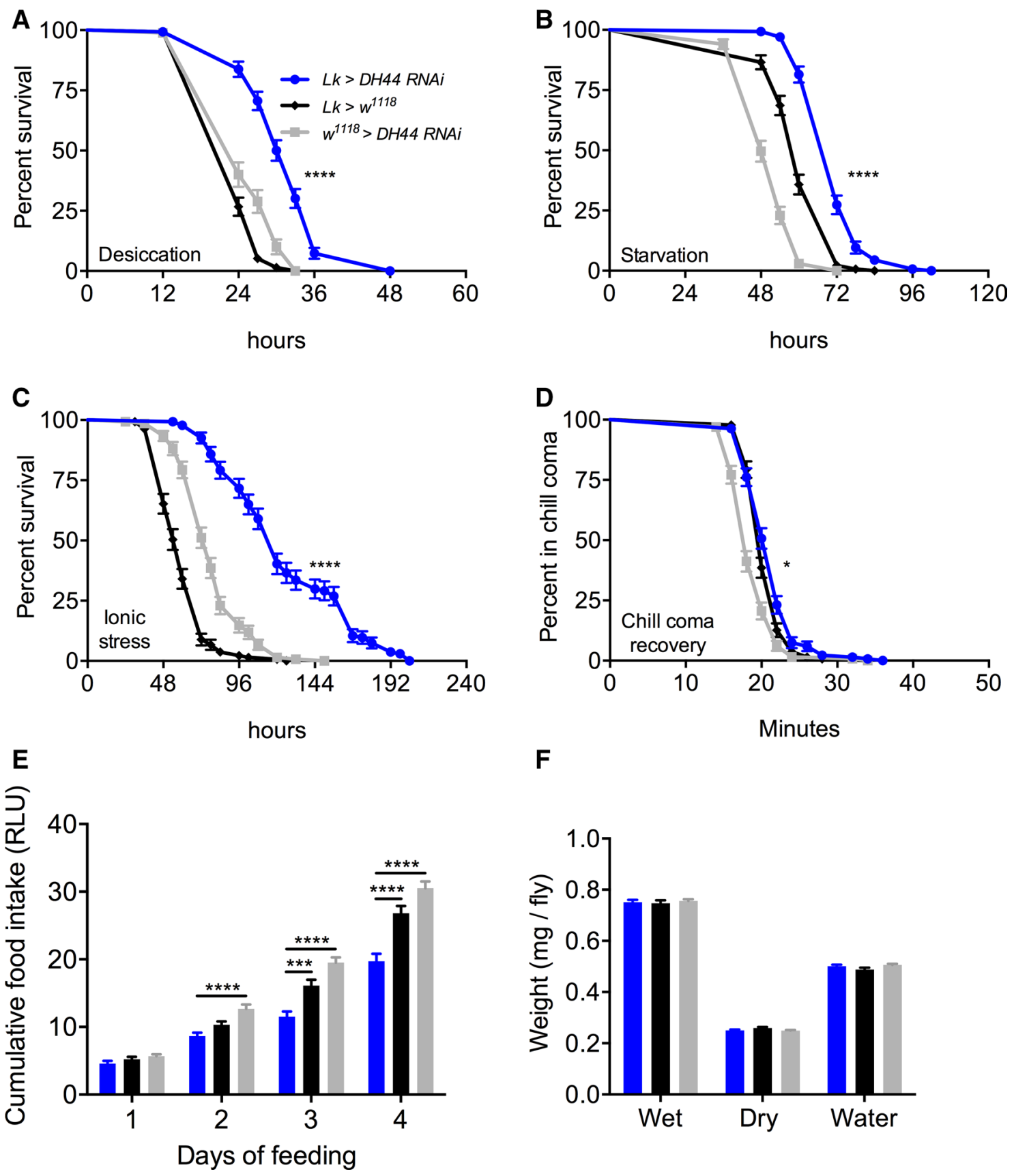

$\mathbf{F}$

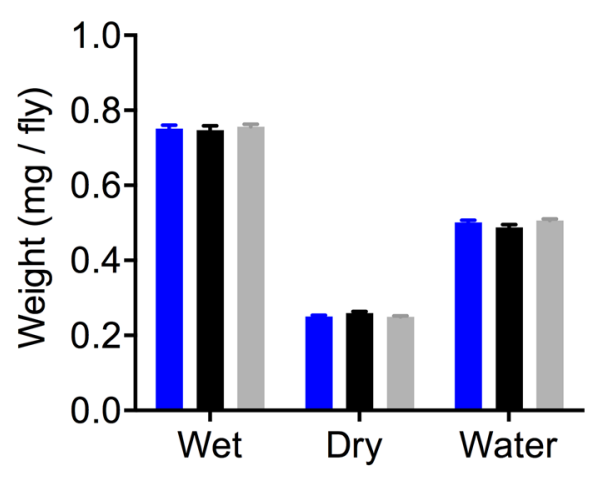

Fig. 7 Knockdown of $D H 44$ using Lk-GAL4 impacts stress resistance and feeding in Drosophila. Lk-GAL4-driven DH44 knockdown results in a significant increase in survival compared to control flies under a desiccation, b starvation, and $\mathbf{c}$ ionic stress (artificial food supplemented with $4 \% \mathrm{NaCl}$ ). Data are presented in survival curves and the error bars represent standard error $(* * * * p<0.0001$, as assessed by log-rank (Mantel-Cox) test. d $\mathrm{DH} 44$ knockdown causes a small delay in chill coma recovery. $\left({ }^{*} p<0.05\right.$, as assessed by log-

rank (Mantel-Cox) test. e Flies with $\mathrm{DH} 44$ knockdown feed less compared to control flies in capillary feeding (CAFE) assay. Results are presented as cumulative food intake over 4 days. (***p $<0.001$, $* * * * p<0.0001$, as assessed by One-way ANOVA). f There is no significant difference in wet weight, dry weight, and water content of DH44-knockdown and control flies. Legend for b-f is the same as the one in a

both $D H 44-R N A i$ and $L k-R N A i$ in these cells increase resistance to desiccation, starvation, and ionic stress. This suggests that diminishing the release of these two peptides from ABLKs is sufficient for this phenotype to occur. However,

food intake is not affected by LK knockdown in ABLKs, whereas DH44 knockdown diminishes feeding, and conversely the knockdown of LK in ABLKs results in increased body water content that is not seen after $D H 44-R N A i$. Thus, 

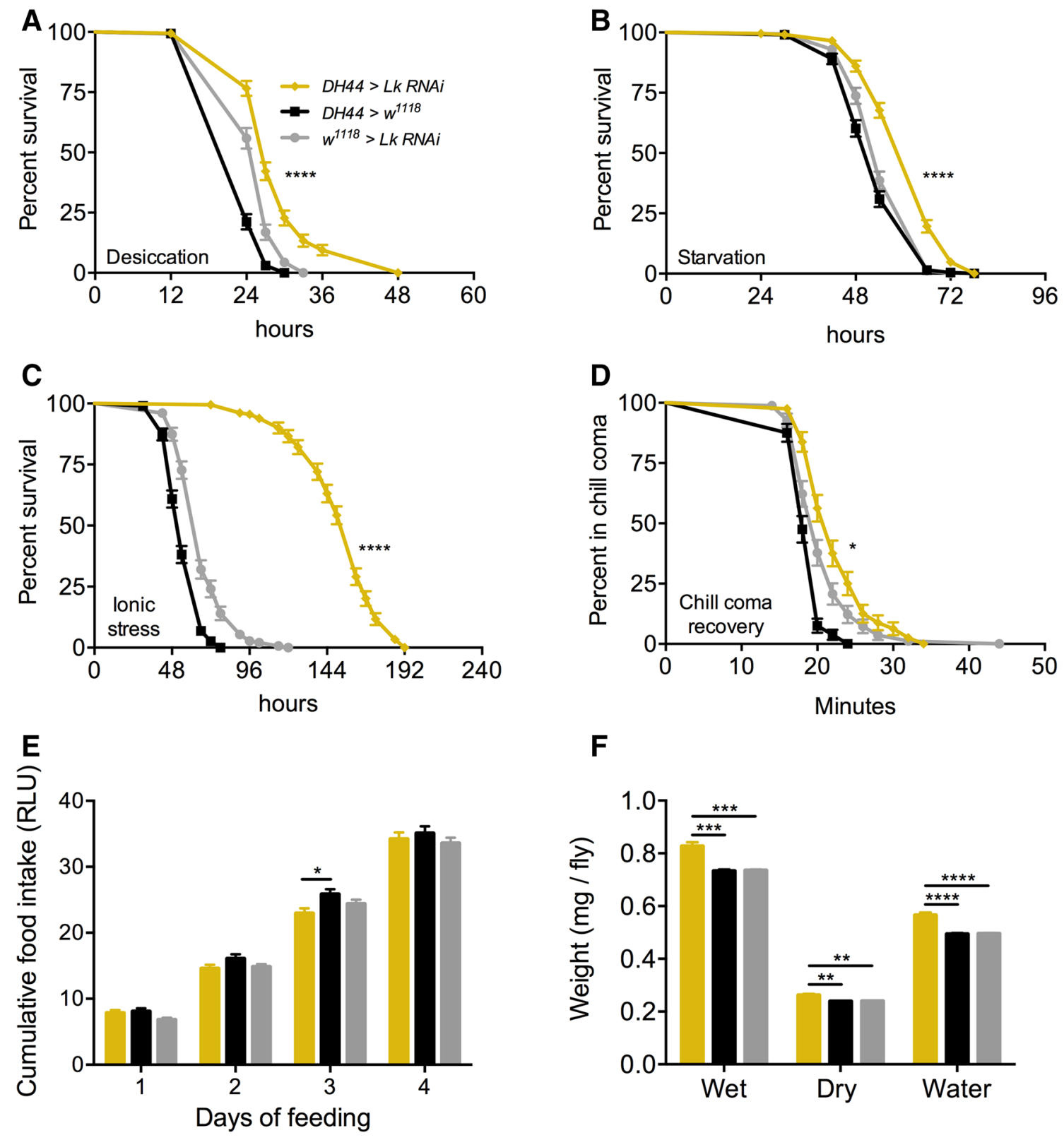

Fig. 8 Knockdown of $L k$ using DH44-GAL4 impacts stress resistance and water content of Drosophila. DH44-GAL4-driven $L k$ knockdown results in a significant increase in survival compared to control flies under a desiccation, b starvation, and $\mathbf{c}$ ionic stress (artificial food supplemented with $4 \% \mathrm{NaCl}$ ). Data are presented in survival curves and the error bars represent standard error $(* * * * p<0.0001$, as assessed by log-rank (Mantel-Cox) test. d $L k$ knockdown results in a delayed recovery from chill coma. $\left({ }^{*} p<0.05\right.$, as assessed by

the two colocalized peptides appear to display similar systemic actions, but differ with respect to feeding and water retention. When knocking down LK in all LK neurons, we obtained a very similar set of effects to those when we targeted only the ABLKs, indicating that in the assays we performed in our study the other two sets of LK neurons (LHLK and SELK) played a minimal role.

log-rank (Mantel-Cox) test. e There is no significant difference (oneway ANOVA) in feeding as measured by capillary feeding (CAFE) assay between $L k$ knockdown and control flies. Results are presented as cumulative food intake over 4 days. f Flies with $L k$ knockdown in ABLKs have a higher wet weight and dry weight and retain more water (wet weight minus dry weight) compared to control flies. $(* * p<0.01, * * * p<0.001, * * * * p<0.0001$, as assessed by One-way ANOVA). Legend for $\mathbf{b}-\mathbf{f}$ is the same as the one in $\mathbf{a}$

Interestingly, knockdown of DH44 in ABLKs increases resistance to desiccation and decreases feeding, but we failed to see these effects when we diminished DH44 in all DH44 neurons. This is consistent with previous work where inactivation or activation of DH44 neurons had no effect on food intake [37]. Perhaps, the effects seen following ABLK manipulations could be compensated by action of the six 
Fig. 9 LK and DH44 peptide application results in an additive response on fluid secretion by Malpighian tubules (MTs) ex vivo. a Secretion rates of MTs incubated with $10^{-7} \mathrm{M}$ DH44 ( $n=28), 10^{-10}$ M LK $(n=25)$, a combination of both $10^{-7} \mathrm{M} \mathrm{DH} 44$ and $10^{-10} \mathrm{M}$ LK $(n=23)$, or no treatment/basal $(n=14)$. b Secretion rates of MTs incubated with $10^{-9} \mathrm{M}$ DH44 ( $n=14), 10^{-10}$ M LK $(n=25)$, a combination of both $10^{-9} \mathrm{M} \mathrm{DH} 44$ and $10^{-10} \mathrm{M} \mathrm{LK}$ $(n=31)$, or no treatment/basal $(n=13)$. For both $\mathbf{a}$ and $\mathbf{b}$, secretion rates were measured at $10 \mathrm{~min}$ intervals for $30 \mathrm{~min}$ before and after the addition of peptide (indicated with an arrow). Asterisk indicates significantly different secretion rate compared to basal secretion rate (secretion rate prior to the addition of peptide. For further statistics, see Table 4. c, d Change (\%) in secretion determined by comparing the secretion rate over the first $30 \mathrm{~min}$ to the maximum secretion rate following peptide application. The legend and sample size for $\mathbf{c}$ and $\mathbf{d}$ are the same as the one in $\mathbf{a}$ and $\mathbf{b}$, respectively. $\mathbf{e}, \mathbf{f}$ Total fluid secreted for $30 \mathrm{~min}$ following peptide application or no treatment (basal). Note that the amount of total fluid secreted following the addition of both LK $\left(10^{-10} \mathrm{M}\right)$ and DH44 $\left(10^{-7}\right.$ $\mathrm{M})$ is a sum of the total fluid secreted following the addition of each of those peptides separately. $* p<0.05, * * p<0.01$, $* * * p<0.001, * * * * p<0.0001$; Mann-Whitney $U$ test)
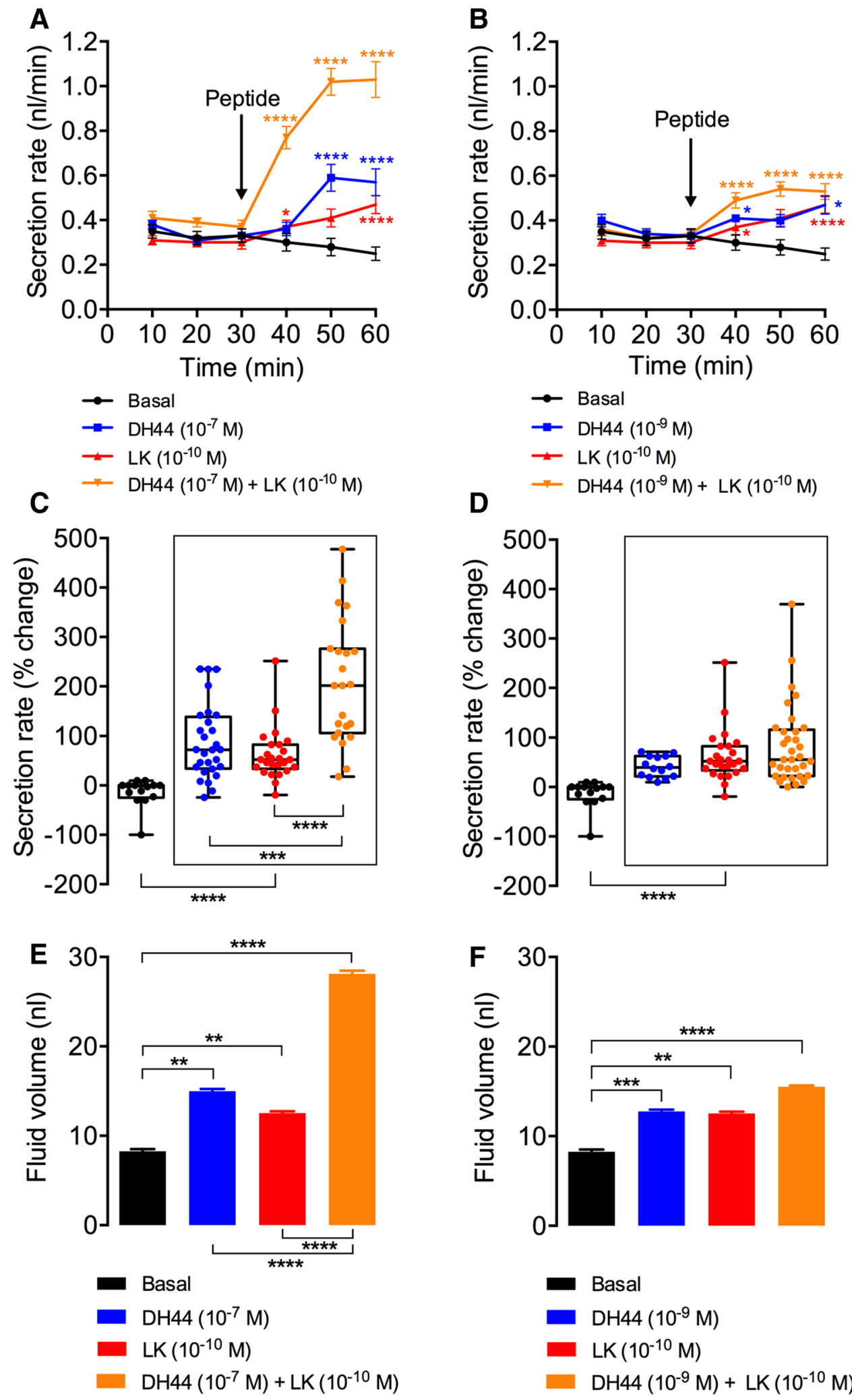

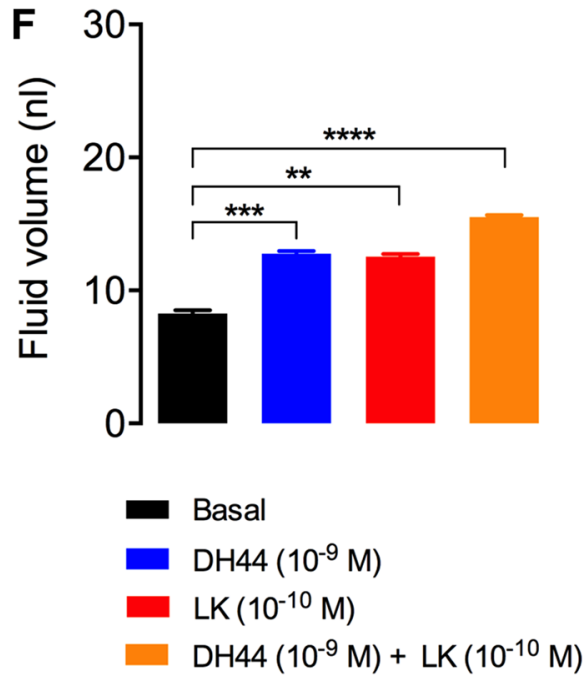

DH44-expressing MNCs in the brain. Similarly, reduction of LK in ABLKs causes a slight increase in time of recovery from chill coma, but this is not noted after global knockdown of LK. This minor difference could possibly be attributed to the strength of the two GAL4 driver lines used and, thus, the efficiency of LK knockdown in ABLKs. 
Table 4 Comparison of secretion rates between various treatments and time points presented in Fig. 9a, b

\begin{tabular}{|c|c|c|c|}
\hline \multirow[t]{2}{*}{ Treatments compared } & \multicolumn{3}{|c|}{ Time (min) } \\
\hline & 40 & 50 & 60 \\
\hline $10^{-7} \mathrm{M}$ DH44 vs $10^{-7} \mathrm{M}$ DH44 $+10^{-10} \mathrm{M}$ LK & $* * * *$ & $* * * *$ & $* * * *$ \\
\hline $10^{-10} \mathrm{M}$ LK vs $10^{-7} \mathrm{M}$ DH $44+10^{-10} \mathrm{M}$ LK & $* * * *$ & $* * * *$ & $* * * *$ \\
\hline $10^{-9} \mathrm{M}$ DH44 vs $10^{-9} \mathrm{M}$ DH44 + $10^{-10} \mathrm{M}$ LK & NS & $* *$ & NS \\
\hline $10^{-10} \mathrm{M}$ LK vs $10^{-9} \mathrm{M}$ DH $44+10^{-10} \mathrm{M}$ LK & $*$ & $*$ & NS \\
\hline
\end{tabular}

$N S$ not significant

${ }^{*} p<0.05,{ }^{* *} p<0.01, * * * * p<0.0001$; Mann-Whitney $U$ test

We also demonstrated that DH44 and LK have additive effects on fluid secretion in MTs. It is likely that these two colocalized peptides are released together and act on the MTs where they target different cell types, receptors, signaling systems, and effectors to regulate fluid secretion [33, 34]. The action of these peptides on the MTs may also in part be responsible for the regulation of stress responses seen in our assays, as shown earlier for CAPA peptide and DH44 $[23,57]$. It is, however, not clear whether the altered food intake and water retention after DH44 and LK knockdown, respectively, are direct actions on target tissues or indirect effects caused by altered water and ion regulation in the fly.

Not only do the ABLKs produce two diuretic hormones, but they also seem to be under tight neuronal and hormonal control. Receptors for several neurotransmitters and peptides have been identified on these cells in adults: the serotonin receptor 5-HT1B, LK receptor (LkR), and the insulin receptor dInR [24, 29]. Knockdown of the 5-HT1B receptor in ABLK neurons diminished LK expression, increased desiccation resistance, and diminished food intake, but manipulations of dInR expression in these cells generated no changes in physiology in the tests performed [24]. In larvae, all ABLKs colocalize LK and DH44, and several receptors have been detected in addition to 5-HT1B [24, 30] and dInR [29], namely RYamide receptor [32], SIFamide receptor [31], and the ecdysis-triggering hormone (ETH) receptor ETHR-A [28]. However, the expression of these receptors on adult ABLKs has so far not been investigated. Interestingly, the functions of ABLKs in larvae, studied so far, seem to be primarily related to regulating muscle activity and ecdysis motor patterns. The 5-HT-1B receptor on ABLKs was shown to modulate locomotor turning behavior [30], whereas ETH-mediated activation of ETHR-A on ABLKs initiates the pre-ecdysis motor activity [27, 28]. In this context, it is worth noting that during metamorphosis six to eight novel ABLKs differentiate anteriorly in the abdominal ganglia [29, 48], and these are the ones that display the strongest expression of DH44. In adult flies, the ABLKs are neurosecretory cells with restricted arborizations in the CNS, but widespread axon terminations along the abdominal body wall and in the lateral heart nerves, whereas in larvae the same cells send axons that terminate on segmental abdominal muscles, muscle 8 [20]. It is not yet known whether larval ABLKs are involved in the regulation of diuresis and other related physiological functions in vivo, but certainly larval functions in locomotion and ecdysis behavior are specific to that developmental stage. Thus, it seems that there is a developmental switch of function in this set of peptidergic neuroendocrine cells.

In summary, we show that a set of abdominal neuroendocrine cells, ABLKs, co-expressing DH44 and LK, are sufficient for regulation of resistance to desiccation, starvation and ionic stress, as well as modulating feeding and water content in the body. These ABLKs represent a subset of neurons that express DH44 and LK, and the functions of the remaining neurons are yet to be determined.

Acknowledgements The authors would like to acknowledge Dr. Yiting Liu and Dr. Olga Kubrak for very helpful advice and valuable discussions. We are grateful to the Bloomington Drosophila Stock Center, the Vienna Drosophila Resource Center, and Drs. Jan A. Veenstra, Pilar Herrero, Young Joon Kim, and Michael Texada for providing flies and reagents. Stina Höglund and the Imaging Facility at Stockholm University (IFSU) are acknowledged for maintenance of the confocal microscopes. This work was supported by a European Commission Horizon 2020, Research and Innovation Grant 634361.

Author contributions $\quad \mathrm{MZ}, \mathrm{SAD}$, and DRN: designed the research; MZ and RM: performed experiments and analyzed data; MZ and DRN: wrote the manuscript with input from the other authors; DRN and SAD: obtained funding; DRN: supervised the study.

\section{Compliance with ethical standards}

Conflict of interest The authors declare that they have no conflict of interest.

Open Access This article is distributed under the terms of the Creative Commons Attribution 4.0 International License (http://creativecommons.org/licenses/by/4.0/), which permits unrestricted use, distribution, and reproduction in any medium, provided you give appropriate credit to the original author(s) and the source, provide a link to the Creative Commons license, and indicate if changes were made.

\section{References}

1. Nässel DR, Winther AM (2010) Drosophila neuropeptides in regulation of physiology and behavior. Prog Neurobiol 92(1):42-104. doi:10.1016/j.pneurobio.2010.04.010

2. Schoofs L, De Loof A, Van Hiel MB (2017) Neuropeptides as regulators of behavior in insects. Annu Rev Entomol 62(62):35-52. doi:10.1146/annurev-ento-031616-035500

3. Schooley DA, Horodyski FM, Coast GM (2012) Hormones controlling homeostasis in insects. In: Gilbert LI (ed) Insect endocrinology. Academic Press, San Diego, pp 366-429. doi:10.1016/ B978-0-12-384749-2.10009-3 
4. Taghert PH, Nitabach MN (2012) Peptide neuromodulation in invertebrate model systems. Neuron 76(1):82-97. doi:10.1016/j. neuron.2012.08.035

5. Itskov PM, Ribeiro C (2013) The dilemmas of the gourmet fly: the molecular and neuronal mechanisms of feeding and nutrient decision making in Drosophila. Front Neurosci 7:12. doi:10.3389/ fnins.2013.00012

6. Murphy KR, Deshpande SA, Yurgel ME, Quinn JP, Weissbach JL, Keene AC, Dawson-Scully K, Huber R, Tomchik SM, Ja WW (2016) Postprandial sleep mechanics in Drosophila. Elife. doi:10.7554/eLife.19334

7. Pool AH, Scott K (2014) Feeding regulation in Drosophila. Curr Opin Neurobiol 29:57-63. doi:10.1016/j.conb.2014.05.008

8. Saper CB, Chou TC, Elmquist JK (2002) The need to feed: homeostatic and hedonic control of eating. Neuron 36(2):199-211

9. Zeltser LM, Seeley RJ, Tschop MH (2012) Synaptic plasticity in neuronal circuits regulating energy balance. Nat Neurosci 15(10):1336-1342. doi:10.1038/nn.3219

10. Chen J, Reiher W, Hermann-Luibl C, Sellami A, Cognigni P, Kondo S, Helfrich-Forster C, Veenstra JA, Wegener C (2016) Allatostatin a signalling in Drosophila regulates feeding and sleep and is modulated by PDF. PLoS Genet 12(9):e1006346. doi:10.1371/journal.pgen.1006346

11. Dow JA (2009) Insights into the Malpighian tubule from functional genomics. J Exp Biol 212(Pt 3):435-445. doi:10.1242/ jeb.024224

12. Halberg KA, Terhzaz S, Cabrero P, Davies SA, Dow JA (2015) Tracing the evolutionary origins of insect renal function. Nat Commun 6:6800. doi:10.1038/ncomms7800

13. Kean L, Cazenave W, Costes L, Broderick KE, Graham S, Pollock VP, Davies SA, Veenstra JA, Dow JA (2002) Two nitridergic peptides are encoded by the gene capability in Drosophila melanogaster. Am J Physiol Regul Integr Comp Physiol 282(5):R1297-R1307. doi:10.1152/ajpregu.00584.2001

14. Alfa RW, Kim SK (2016) Using Drosophila to discover mechanisms underlying type 2 diabetes. Dis Model Mech 9(4):365376. doi: $10.1242 / \mathrm{dmm} .023887$

15. Owusu-Ansah E, Perrimon N (2014) Modeling metabolic homeostasis and nutrient sensing in Drosophila: implications for aging and metabolic diseases. Dis Model Mech 7(3):343-350. doi:10.1242/dmm.012989

16. Padmanabha D, Baker KD (2014) Drosophila gains traction as a repurposed tool to investigate metabolism. Trends Endocrinol Metab 25(10):518-527. doi:10.1016/j.tem.2014.03.011

17. Brogiolo W, Stocker H, Ikeya T, Rintelen F, Fernandez R, Hafen E (2001) An evolutionarily conserved function of the Drosophila insulin receptor and insulin-like peptides in growth control. Curr Biol 11(4):213-221

18. Kim SK, Rulifson EJ (2004) Conserved mechanisms of glucose sensing and regulation by Drosophila corpora cardiaca cells. Nature 431(7006):316-320. doi:10.1038/nature02897

19. Nässel DR, Enell LE, Santos JG, Wegener C, Johard HA (2008) A large population of diverse neurons in the Drosophila central nervous system expresses short neuropeptide F, suggesting multiple distributed peptide functions. BMC Neurosci 9:90. doi:10.1186/1471-2202-9-90

20. Cantera R, Nässel DR (1992) Segmental peptidergic innervation of abdominal targets in larval and adult dipteran insects revealed with an antiserum against leucokinin I. Cell Tissue Res 269(3):459-471

21. De Haro M, Al-Ramahi I, Benito-Sipos J, Lopez-Arias B, Dorado B, Veenstra JA, Herrero P (2010) Detailed analysis of leucokininexpressing neurons and their candidate functions in the Drosophila nervous system. Cell Tissue Res 339(2):321-336. doi:10.1007/ s00441-009-0890-y
22. Al-Anzi B, Armand E, Nagamei P, Olszewski M, Sapin V, Waters C, Zinn K, Wyman RJ, Benzer S (2010) The leucokinin pathway and its neurons regulate meal size in Drosophila. Curr Biol 20(11):969-978. doi:10.1016/j.cub.2010.04.039

23. Cannell E, Dornan AJ, Halberg KA, Terhzaz S, Dow JA, Davies SA (2016) The corticotropin-releasing factor-like diuretic hormone 44 (DH44) and kinin neuropeptides modulate desiccation and starvation tolerance in Drosophila melanogaster. Peptides 80:96-107. doi:10.1016/j.peptides.2016.02.004

24. Liu Y, Luo J, Carlsson MA, Nässel DR (2015) Serotonin and insulin-like peptides modulate leucokinin-producing neurons that affect feeding and water homeostasis in Drosophila. J Comp Neurol 523(12):1840-1863. doi:10.1002/cne.23768

25. Lopez-Arias B, Dorado B, Herrero P (2011) Blockade of the release of the neuropeptide leucokinin to determine its possible functions in fly behavior: chemoreception assays. Peptides 32(3):545-552. doi:10.1016/j.peptides.2010.07.002

26. Murakami K, Yurgel ME, Stahl BA, Masek P, Mehta A, Heidker R, Bollinger W, Gingras RM, Kim YJ, Ja WW, Suter B, DiAngelo JR, Keene AC (2016) translin is required for metabolic regulation of sleep. Curr Biol 26(7):972-980. doi:10.1016/j.cub.2016.02.013

27. Kim DH, Han MR, Lee G, Lee SS, Kim YJ, Adams ME (2015) Rescheduling behavioral subunits of a fixed action pattern by genetic manipulation of peptidergic signaling. PLoS Genet 11(9):e1005513. doi:10.1371/journal.pgen.1005513

28. Kim YJ, Zitnan D, Galizia CG, Cho KH, Adams ME (2006) A command chemical triggers an innate behavior by sequential activation of multiple peptidergic ensembles. Curr Biol 16(14):13951407. doi:10.1016/j.cub.2006.06.027

29. Luo J, Liu Y, Nässel DR (2013) Insulin/IGF-regulated size scaling of neuroendocrine cells expressing the bHLH transcription factor Dimmed in Drosophila. PLoS Genet 9(12):e1004052. doi:10.1371/journal.pgen.1004052

30. Okusawa S, Kohsaka H, Nose A (2014) Serotonin and downstream leucokinin neurons modulate larval turning behavior in Drosophila. J Neurosci 34(7):2544-2558. doi:10.1523/ JNEUROSCI.3500-13.2014

31. Sellami A, Veenstra JA (2015) SIFamide acts on fruitless neurons to modulate sexual behavior in Drosophila melanogaster. Peptides 74:50-56. doi:10.1016/j.peptides.2015.10.003

32. Veenstra JA, Khammassi H (2017) Rudimentary expression of RYamide in Drosophila melanogaster relative to other Drosophila species points to a functional decline of this neuropeptide gene. Insect Biochem Mol Biol 83:68-79. doi:10.1016/j. ibmb.2017.03.001

33. Cabrero P, Radford JC, Broderick KE, Costes L, Veenstra JA, Spana EP, Davies SA, Dow JA (2002) The Dh gene of Drosophila melanogaster encodes a diuretic peptide that acts through cyclic AMP. J Exp Biol 205(Pt 24):3799-3807

34. Terhzaz S, O'Connell FC, Pollock VP, Kean L, Davies SA, Veenstra JA, Dow JA (1999) Isolation and characterization of a leucokinin-like peptide of Drosophila melanogaster. J Exp Biol 202(Pt 24):3667-3676

35. Lee KM, Daubnerova I, Isaac RE, Zhang C, Choi S, Chung J, Kim YJ (2015) A neuronal pathway that controls sperm ejection and storage in female Drosophila. Curr Biol 25(6):790-797. doi:10.1016/j.cub.2015.01.050

36. Cavanaugh DJ, Geratowski JD, Wooltorton JR, Spaethling JM, Hector CE, Zheng X, Johnson EC, Eberwine JH, Sehgal A (2014) Identification of a circadian output circuit for rest: activity rhythms in Drosophila. Cell 157(3):689-701. doi:10.1016/j. cell.2014.02.024

37. Dus M, Lai JS, Gunapala KM, Min S, Tayler TD, Hergarden AC, Geraud E, Joseph CM, Suh GS (2015) Nutrient sensor in the brain 
directs the action of the brain-gut axis in Drosophila. Neuron 87(1):139-151. doi:10.1016/j.neuron.2015.05.032

38. Brand AH, Perrimon N (1993) Targeted gene expression as a means of altering cell fates and generating dominant phenotypes. Development 118(2):401-415

39. Asahina K, Watanabe K, Duistermars BJ, Hoopfer E, Gonzalez CR, Eyjolfsdottir EA, Perona P, Anderson DJ (2014) Tachykinin-expressing neurons control male-specific aggressive arousal in Drosophila. Cell 156(1-2):221-235. doi:10.1016/j. cell.2013.11.045

40. Jenett A, Rubin GM, Ngo TT, Shepherd D, Murphy C, Dionne H, Pfeiffer BD, Cavallaro A, Hall D, Jeter J, Iyer N, Fetter D, Hausenfluck JH, Peng H, Trautman ET, Svirskas RR, Myers EW, Iwinski ZR, Aso Y, DePasquale GM, Enos A, Hulamm P, Lam SC, Li HH, Laverty TR, Long F, Qu L, Murphy SD, Rokicki K, Safford T, Shaw K, Simpson JH, Sowell A, Tae S, Yu Y, Zugates CT (2012) A GAL4-driver line resource for Drosophila neurobiology. Cell Rep 2(4):991-1001. doi:10.1016/j. celrep.2012.09.011

41. Dietzl G, Chen D, Schnorrer F, Su KC, Barinova Y, Fellner M, Gasser B, Kinsey K, Oppel S, Scheiblauer S, Couto A, Marra V, Keleman K, Dickson BJ (2007) A genome-wide transgenic RNAi library for conditional gene inactivation in Drosophila. Nature 448(7150):151-156. doi:10.1038/nature05954

42. Pfeiffer BD, Truman JW, Rubin GM (2012) Using translational enhancers to increase transgene expression in Drosophila. Proc Natl Acad Sci USA 109(17):6626-6631. doi:10.1073/ pnas.1204520109

43. Kubrak OI, Lushchak OV, Zandawala M, Nässel DR (2016) Systemic corazonin signalling modulates stress responses and metabolism in Drosophila. Open Biol. doi:10.1098/rsob.160152

44. Nässel DR, Cantera R, Karlsson A (1992) Neurons in the cockroach nervous system reacting with antisera to the neuropeptide leucokinin I. J Comp Neurol 322(1):45-67. doi:10.1002/ cne.903220105

45. Schindelin J, Arganda-Carreras I, Frise E, Kaynig V, Longair M, Pietzsch T, Preibisch S, Rueden C, Saalfeld S, Schmid B, Tinevez JY, White DJ, Hartenstein V, Eliceiri K, Tomancak P, Cardona A (2012) Fiji: an open-source platform for biological-image analysis. Nat Methods 9(7):676-682. doi:10.1038/nmeth.2019

46. Kahsai L, Kapan N, Dircksen H, Winther AM, Nässel DR (2010) Metabolic stress responses in Drosophila are modulated by brain neurosecretory cells that produce multiple neuropeptides. PLoS One 5(7):e11480. doi:10.1371/journal.pone.0011480

47. Dow JA, Maddrell SH, Gortz A, Skaer NJ, Brogan S, Kaiser K (1994) The Malpighian tubules of Drosophila melanogaster: a novel phenotype for studies of fluid secretion and its control. J Exp Biol 197:421-428

48. Alvarez-Rivero J, Moris-Sanz M, Estacio-Gomez A, MontoliuNerin M, Diaz-Benjumea FJ, Herrero P (2017) Variability in the number of abdominal leucokinergic neurons in adult Drosophila melanogaster. J Comp Neurol 525(3):639-660. doi:10.1002/ cne. 24093

49. Dircksen H, Tesfai LK, Albus C, Nässel DR (2008) Ion transport peptide splice forms in central and peripheral neurons throughout postembryogenesis of Drosophila melanogaster. J Comp Neurol 509(1):23-41. doi:10.1002/cne.21715

50. Cognigni P, Bailey AP, Miguel-Aliaga I (2011) Enteric neurons and systemic signals couple nutritional and reproductive status with intestinal homeostasis. Cell Metab 13(1):92-104. doi:10.1016/j.cmet.2010.12.010

51. Chintapalli VR, Wang J, Dow JA (2007) Using FlyAtlas to identify better Drosophila melanogaster models of human disease. Nat Genet 39(6):715-720. doi:10.1038/ng2049

52. Bhatt G, da Silva R, Nachman RJ, Orchard I (2014) The molecular characterization of the kinin transcript and the physiological effects of kinins in the blood-gorging insect, Rhodnius prolixus. Peptides 53:148-158. doi:10.1016/j.peptides.2013.04.009

53. Cabrero P, Terhzaz S, Romero MF, Davies SA, Blumenthal EM, Dow JA (2014) Chloride channels in stellate cells are essential for uniquely high secretion rates in neuropeptide-stimulated Drosophila diuresis. Proc Natl Acad Sci USA 111(39):14301-14306. doi:10.1073/pnas.1412706111

54. Chen Y, Veenstra JA, Hagedorn H, Davis NT (1994) Leucokinin and diuretic hormone immunoreactivity of neurons in the tobacco hornworm, Manduca sexta, and co-localization of this immunoreactivity in lateral neurosecretory cells of abdominal ganglia. Cell Tissue Res 278(3):493-507

55. Thompson KS, Rayne RC, Gibbon CR, May ST, Patel M, Coast GM, Bacon JP (1995) Cellular colocalization of diuretic peptides in locusts: a potent control mechanism. Peptides 16(1):95-104

56. Te Brugge VA, Nässel DR, Coast GM, Schooley DA, Orchard I (2001) The distribution of a kinin-like peptide and its co-localization with a CRF-like peptide in the blood-feeding bug, Rhodnius prolixus. Peptides 22(2):161-173

57. Terhzaz S, Teets NM, Cabrero P, Henderson L, Ritchie MG, Nachman RJ, Dow JA, Denlinger DL, Davies SA (2015) Insect capa neuropeptides impact desiccation and cold tolerance. Proc Natl Acad Sci USA 112(9):2882-2887. doi:10.1073/pnas.1501518112 